\title{
Study on the Roles of Knowledge-enabled Human Resource in the Innovation Driven Development under the HRA View
}

\author{
Yehong He \\ Henan Institute of Education \\ Zhengzhou, China 450046
}

\begin{abstract}
The 18th National Congress represents clearly that scientific and technological innovation provides strategic support for raising the productive forces and boosts the overall national strength, and we must give it top priority in overall national development. To implement the innovation driven development strategy will not only have a strategic significance for China to form new advantages in the international competition and intensify the long term drive for development but also have a practical significance to improve the economic growth quality and benefit and speed up the transformation of economic development mode. The scientific and technological innovation has multiplier effects, which can be directly transformed into practical productivity also increase the overall social productivity level via the scientific and technological penetration which may enlarge the productive power of production factors. Nowadays, the hardware investment such as infrastructure has formed an initial scale in China, however, what we should not neglect is that the acceptance, fostering and excitation of knowledge-enabled human resource play an irreplaceable role in the enterprise's core competitive power and the development of regional economy. Studying how to seek, foster and excite talents under HRA view and intensifying the study on the knowledgeenabled human resource leading the innovation driven development will have a far-reaching influence to the economic and social development in China.
\end{abstract}

Keywords-HRA, knowledge-enabled human resource, innovation driven, economic development

\section{THEORIES CONCERNING THE KNOWLEDGE-ENABLED HUMAN RESOURCE}

\section{A. Annotation about Knowledge-Enabled Human Resource at Home and Abroad}

As for the connotation of knowledge-enabled human resource, the earliest and most representative view was stated by $\mathrm{P}$. Druker, a famous American management master, according to the economic features of that time and the production development in 1959, in his opinion, the knowledge-enabled human resource refers to "those who master and use symbols and concepts, make use of knowledge and information", namely managers or executive managers. Tom Davenport, an American knowledge management expert, stated that the knowledge-enabled human resource is a group of "people who make initial innovations in work, distribute and apply knowledge". France Horibe, a Canadian scholar thought that the knowledge-enabled human resource shall be those who create fortunes with more brains used than hands. Anderson, a famous international consultancy agency indicated via researches that the knowledge-enabled employees shall include the following: (1) experts; (2) senior talents with professional skills; (3) medium and high level management. At present, with the new normal economy, due to the influence by new economic modes especially the Internet economy, the author thinks that the knowledge-enabled human resource shall be those who receive higher education and undertake heavier brainwork during the value production. It is a group who use wisdom to create value in a team after social labor distribution. Under the background of knowledge economic globalization and integration, the knowledge-enable human resource owns a higher capability to learn new knowledge and make innovations, and they can use modern scientific knowledge to improve the work efficiency. As for as this understanding, we can expand the knowledge-enabled human resources to the workers with brainwork input and output as symbols during and after completion of the work. They own the most valuable invisible assets, namely knowledge.

\section{B. Characteristics of Knowledge-Enabled Human Resource}

1) Independence. The knowledge-enabled human resource owns stronger consciousness of independence, in the coming uncertain environment, all kinds of occasions may happen at any time, the knowledge-enabled human resource may face problems and make creative thoughts via brains, accumulate and create new knowledge achievements continuously.

2) Professional technical background and high individual quality. Most of the knowledge-enabled employees receive higher education, owning higher degree and mastering higher professional knowledge and skills, just due to the higher education received, the knowledge-enabled employees own higher individual quality such as open academic field and stronger learning capability.

3) Clear goal guide and sense of realizing value. Differing from traditional laborers, the knowledge-enabled 
employees have received higher education, and the differences in the work nature, method and environment have formed them unique though methods, accordingly they have clear work goal guide, and they regard continuous accumulation of new knowledge, regard the development of career of their own, so they pay higher attentions to the competence improvement and opportunities for development. What they focus on is not the salary but trying to exert their skills and obtain achievements, and they emphasize the achievement of the value of their own and expect to be recognized and respected by the society. According to Maslow's need hierarchy theory, the knowledge-enabled employees pursue little of low hierarchy need such as physiology and safety, compared to general employees, the knowledge-enabled employees have higher hierarchy needs, and they emphasize the realization of the value of their own. They have strong desire for success and expect to be recognized by organizations and the society, they are addicted to challenging and creative work and desire to reveal individual value and achieve the value of their own via the work. The high senses of achievements and identification are internal driving factors.

4) The work course difficult to supervise and control, the work achievements uneasy to measure and assess directly. The knowledge-enabled employees are engaged in creative knowledge work in an unsteady and uncertain environment, and the work course generally has no fixed flow or procedures, which take on high randomness and personal control, and even the working places differ greatly from traditional fixed workshops and offices, and the inspiration and originality may occur at non-working times and places. The work achievements are often embodied through some thought, originality, technical invention and management innovation, which need the assistance and cooperation from teams. According to the characteristics mentioned above, the work achievements of knowledge-enabled employees especially individuals cannot be often measured through general economic benefit indices.

5) High employment flow. Since the knowledge-enabled employees own special production factors, namely knowledge that they have in brains, in addition, they have capabilities to accept new jobs and tasks, so they have higher options for occupations than traditional workers. Once the existing work has no adequate abstraction or no opportunities and development space for individuals, they will select other employers for new work opportunities. Accordingly the knowledge-enabled employees are more loyal to commitments to the occupation but not to enterprises.

\section{ANALYSIS ON THE QUALITY STRUCTURE OF HUMAN- ENABLED HUMAN RESOURCE UNDER HRA VIEW}

\section{A. Introduction to Personal Quality}

Generally the personal quality consists of five aspects, namely body quality, thought and political quality, capability quality, psychology quality and cultural knowledge quality

1) Body quality. The body quality is a basic condition for an individual, if having no perfect physique and healthy body, the person will loose the basic condition for career success. The body quality mainly includes body condition, physical strength, physical performance, body form and energy.

2) Thought and political quality. The thought and political quality is a necessary basic condition and quality for an individual to engage in social and political activities, which is a complex manifestation of a person in political thought, political direction, political position, political view, political attitude and political belief. The thought and political quality contains many factors with rich and profound meaning, which generally include political direction, political position, political view, political discipline, political judgment, political perspicacity and political skills.

3) Cultural knowledge quality. Knowledge quality refers to the necessary basic and professional knowledge for a person to do a job. The basic knowledge is a base for the knowledge structure of human resource. It is a degree for a person to master the basic theory, basic knowledge and basic methods. Professional knowledge is a main symbol for the knowledge structure talents in the professional field.

4) Capability quality. Speaking in a broad sense, the capability is a skill for a person to know and rebuild objective world and subjective world. Speaking in a narrow sense, it refers to a subjective condition to competent for a job, which is embodied in psychological characteristics owned to complete some activity and influence directly the activity efficiency. The capability is a psychological characteristic to complete some activity yet the psychological characteristics in an activity are not all capabilities. The capability quality is a complex concept, and it is an organic integration of technical capability, decisionmaking capability, communication capability and so on. It includes scientific decision-making capability, organization and leadership capability, communication capability, and talent employment and arrangement capability. Judging from the main body of the capability, the capabilities vary with the posts, the high level posts need concepts for decision making, the medium level posts need higher communication capabilities, and the low level posts focus on technique and skills. However, the three capabilities are required and prepared at the same time, which only differ in proportion. As far as the capability quality structure, the knowledgeenabled human resource shall have the following characteristics (1) perpetual learning; (2) information innovation; (3) forward looking; (4) strong motive for achievements.

5) Psychology quality. The so called psychological quality refers to the culture of psychological quality of a person in feeling, imagination, thought, concept, emption, will and interest. It is a concept with wide contents, involving in the nature, interest, motive, will and emotion of a person. The fine psychological quality refers to healthy psychology or owning healthy psychology. 


\section{QUALITY STRUCTURE TO BE INTENSIFIED FOR KNOWLEDGE-ENABLED HUMAN RESOURCE}

Just due to the "crown effect" of the knowledge-enabled human resource in the knowledge quality and capability quality, many enterprises neglect the quality reinforcement in other aspects for the knowledge-enabled human resource, which just bring strong adverse effect to the development of the enterprise and even the society.

\section{A. Professional Ethics Quality}

The professional ethics quality is the most important quality in all qualities, which shall be also emphasized by the enterprise on high level knowledge-enabled employees.

Since the knowledge-enabled employees master a lot of technique or other data and information concerning the enterprise, and the knowledge-enabled employees being high level management control the distribution and use rights of the enterprise's resources, and the lack of analysis and judgment capabilities in professional ethics quality only case serious hard to the enterprise's key decisions and plans.

\section{B. Public Communication Quality}

Most of knowledge-enabled employees work as team, and they should have strong communication quality and interpersonal interaction. During the work, both taciturnity and self-opinion will influence the work efficiency. Due to the accelerated renewal of knowledge, the team shall be an open and continuously learning organization, if any employee disagrees to share the knowledge of his own with others, it will influence the progress of the whole team.

\section{Management Quality}

Data survey shows that a typical characteristic of knowledge-enabled human resource is outstanding technical achievement and higher business capability, and the persons concerned will be promoted to the management, however, due to the lack of management principle, management method and management skills should be prepared, the team work falls behind and the team goals fail to be achieved. Furthermore, due to the lack of concept skill and communication skill, the blind commands not only keep the knowledge-enabled employees confused but also cause huge waste of resources.

\section{Body Quality}

The knowledge-enabled employees have strong pursuit for self-realization and value increment, expecting the acceptance by leaders and colleagues and desiring for career success. In order to achieve the goal early, they often establish a over high standard for professional career, work lustily and self-boost pressure and keep continuous innovation and progress dauntless, despite it is over the self capability but they still ask for too much from themselves. As such, the body is kept under high pressure for a long time, with the body conditions not considered, the long term accumulation and over fatigue have made most of the knowledge-enabled human resource under sub-healthy conditions.
Besides, though the knowledge-enabled human resource has stronger needs for success, yet they are in the lack of favorable psychology to endure, and the poor capabilities to endure frustration cause them to be defeated by a short time failure, which forms a sub-health in psychology.

\section{MEANING OF INNOVATION-DRIVEN DEVELOPMENT} AND ANALYSIS ON THE INTERACTIVE MODES BETWEEN IT AND THE KNOWLEDGE-ENABLED HUMAN RESOURCE

\section{A. The "Innovation-driven Development" Strategy Has Two Meanings:}

First, China's development will be driven by technical innovation in the future but not traditional laborers and resources and energy sources; second, the purpose of innovation is to drive the development. Chinese president $\mathrm{Xi}$ Jinping points out that the innovation is a significant strength to drive the development of a country and a nation. The author thinks that the nature of innovation-drive development is the drive of knowledge-enabled human resource. With the rising of new generation of technical revolution and industrial reforms, the scientific and technical innovation take on new development tendency and characteristics, outdated technologies are replaced by the new ones, and labor intensive technologies are replaced by intellectual technologies, which is an obvious trend. The innovation leads transformation, which means to exert all kinds of resources especially the advantages of knowledgeenabled human resource.

\section{B. Analysis on the Interactive Modes between Knowledge- Enabled Human Resource and Innovation-driven Development}

The nature of innovation-driven development is talent drive, and the talent is the most important key for scientific and technical innovation. The most advance technologies and the leading innovation cannot be separated from the talent and the creative activities of the talents.

The precondition to implement the innovation-driven development strategy is to place the knowledge-enabled human resource on the prior place for scientific and techno local innovation. The enterprise shall rapidly introduce and foster an innovative talent team full innovative spirit in a large scale. Second, the enterprise shall exert what it owns in decision on technical innovation, R\&D investment, research organization and achievement transformation. And it shall gather and introduce talents and meet the talents' demand to the maximum, the key points for human resource affairs in an enterprise shall push talents to the front of innovation drive. Third, set a talent concept in the new time and focus on improving the talent's efficiency. Regard the talent's personal activity and rules of talent growth, and enable the knowledge-enabled human resource to participate in social practice widely. The innovative human resource originates from the practice, and the talents shall be found in the innovative practice, fostered in the innovative activities and gathered in the innovative career. More attentions shall be paid to exertion, abstraction and fostering of talents, and the talent gathering system and mechanism shall be innovated, 
perfect the talents flow, arrangement, evaluation and encouragement and service guarantee mechanism, set up a capability and achievements-orientated talent use mechanism and optimize the talent development environment.

1) The promotion of human resource development to the innovation-driven development. The precondition for innovation-driven development is to keep continuous innovation especially the innovation of key technology and management mechanism. The main body of innovation is enterprise, social organization, family and individual, without excellent human resource, there will be no innovative activities; if there are no innovative activities or low benefits from innovative activities, it will be difficult to achieve the innovation-driven development. On the contrary, if a country or region has rich excellent human resource with rational structure and arrangement, full development and well going mechanism, the innovative activities will certainly bring obvious benefits, and the efficiency of innovation driven economy and overall social development will be consequentially obvious.

2) The promotion of innovation-driven development to the human resource development. Compared to traditional resource drive and capital drive, the innovation drive has huge "magic", and it works as a generator. Experiments show that the economic investment and yield ratio made by the innovation drive may achieve 1:50 or more. However, during the implementation of innovation-driven development strategy, it is a necessity to intensify the scientific and technical system reforms and accelerate the establishment of a scientific and rational national innovation system with activity and efficiency, all of which will rely on the improvement of the strength and quality of human resource development. Accordingly the innovation-driven development is the most efficient internal drive for improving the strength and quality of human resource development. With the requirements of the time, only all measures are taken to lead and gather the social wisdom and strength to the innovative development, can provide powerful driving resource to accelerate the transformation of economic development modes.

\section{To Establish A New Mode to Exert the POSITIVE ROLES OF KNOWLEDGE-ENABLED HUMAN RESOURCE}

Considering the characteristics of knowledge-enabled human resource, its roles in economic development and characteristics of knowledge-enabled human resource stirred at home and abroad, in order to fully stir the work enthusiasm, initiative and creativity, the author thinks that necessary measures can be taken from three aspects in order for efficient adjustment so as to reach an ideal state of resource utilization.

\section{A. Innovation Instructed by Policies at State or Regional Level, Attract Knowledge-enabled Human Resource and Provide Places for Their Development}

1) Intensify the reform via law establishment, and focus on the system innovation applicable for the knowledge- enabled human resource development. First of all, establish and improve the policy mechanism to encourage innovation, the breakthrough and reform of policies will create an innovative culture where human is orientated, individuals are regarded with specialty developed, innovation encouragement and failure forgiveness, accelerate to foster and attract innovative talents, speed up the speed to transform technical achievements, and affirm the market value of scientific research results and talents. Stir the innovative enthusiasm of the society and make the innovative talents to eminent and fully show the innovative benefits. For example, reform the irrational systems in property rights and distribution and speed up the speed of collect patents transformed to the feasible productivity. Second, establish competition systems for talent arrangement, fully exert the basic functions of market mechanism for human resource arrangement, improve the well running and powerful talent market system under instruction and supervision, and promote the optimization of talent structure and raise the talent quality. Third, perfect the talent excitation and guarantee mechanism, insist on the principle of prior efficiency together with fairness, according to the work quantity, quality and efficiency, widen the salary distribution level, and execute high salary for top achievements, and special salary for special post workers. Meanwhile, continuously improve the talents' conditions for work, study and living and remove the disturbance in the rear.

2) With platforms considered to optimize the innovative environment for knowledge-enabled human resource. First of all, form a social composite force as quickly as it can, following the requirements of organization by government, support by departments, market-orientated, enterprise acting as main body and social participation, focus on the construction of talent teams, intensify the innovative consciousness of the people, create cooperative innovation platforms, optimize innovative environment, expand the opening innovation degree so as to form a powerful innovative compound force. And then form a social compound force mechanism where policies lead technical innovation, platforms carry technical innovation, plans support technical innovation and environments serve the technical innovation. Second, form a innovation interlocking mechanism as quickly as it can, take industrial innovation as the core, insist on the enterprise acting as main body and codevelopment of enterprise, scientific research institutions and colleges, and connect the talent fostering closely with team construction, platform construction and industrial development so as to reinforce the independent innovative capabilities. Third, form a scientific distribution and support system of human resource as quickly as it can, insist on the demand oriented, share as the core, service as tenet, systems as guarantee, mutual benefits and win-win as drives, accelerate the construction of technical innovation platforms and technical service platforms such as State-level and provincial-level key labs, engineering research centers, postdoctor research stations, enterprise technical centers, etc. instruct and support social funds to create complex and professional technical innovation incubators, promote the opening and share of key technical facilities, and establish a 
scientific and technical innovation system characterized of rational distribution and efficient running.

3) Implement talent projects, foster and well adjust the knowledge-enabled human resource innovation teams. First of all, foster innovative talents in a large scale, push the adjustment of talent structure strategy, and focus on creating a high level innovative Party and political-led talent team, professional technician team, enterprise operation and management talent team, highly skilled talent team, and practical rural talent team. Try best to create an innovative talent team characterized of adequate number, high quality and rational structure. State or governmental departments shall intensify management on the overall talent market at home, distribution and flow of knowledge-enabled human resource, and execute complex balance control.

\section{B. Improve Enterprise Mechanism and Foster Applicable Selection and Employment Systems for the Knowledge- Enabled Human Resource}

1) Establish standards and select the knowledge-enabled human resource applicable for enterprise development goals. According to the vision and staged goals for development, the enterprise will have different demands for talents, if not considering the enterprise development goals and failing to establish standards to select knowledge-enabled employees and introducing blindly quality knowledge-enabled employees, it is an irresponsibility for the enterprise and the knowledge-enabled human resource, which may cause serious waste of human resource and even other resources of the enterprise. Therefore, as far as the enterprise, high-level management shall have strategic thinking, specify staged development goal and the demands of departments for knowledge-enabled human resource, according to characteristics of posts, establish clear post instruction, specify the post-related work contents, work environment and conditions, as well as standards and requirements to the knowledge-enabled human resource. Execute bidirectional communication between the information and human resource required, if necessary, create corresponding talent quality evaluation model and competence model so as to ensure a definite object for talents' introduction and employment, and place a foundation for the enterprise's talent-post matching goal. Certainly during the establishment of standards, the talent arrangement shall be not kept in the same mode, for excellent talents with innovative potentials generally have strong personality, or the creativity of excellent talents is generally hidden in the unique personality. The creative talents with personal charm are just the most valuable capital and the spring for innovative development for an enterprise. Especially personal characteristics of creative talents shall be known correctly, provide them with comfortable and loose environment for their personality, and enable them to show and exert their wisdom and creative potentials during the free development not limited to a given mode.

2) Enterprises shall regard the characteristics of knowledge-enabled human resource they need, and provide and expand the places for their development. First of all, according to Maslow's need hierarchy and other excitation theories, analyze the demands of knowledge-enabled employees and provide the excitation factors needed in a certain scope. For example the knowledge-enabled human resource is engaged in the creative work in the enterprise, which focuses on independence and autonomy, on the one hand, the enterprise shall give adequate authorization according to the task requirements, and allow employees to establish the optimal work methods that they think but not give specific instruction or supervision, any administrative command and forcible commands are inapplicable. On the other hand, the knowledge-enabled employees shall be provided with funds, materials and personnel needed for independent creative work to ensure the innovative activities and reach the acknowledgement of self value and achieve the goal of self value. Heavy tasks shall be trusted to the knowledge-enabled employees when necessary so as to exert what they can, stir their internal potentials and inspire the great personal activity. Second, the enterprise shall consider the professional career plan of knowledge-enabled human resource and provide training for renewal of knowledge and skills. Employees' training and education are power and spring for the continuous development of employees, and the training and education the enterprise provides will become one of the important conditions to attract and retain talents. Accordingly the enterprise may conduct training throughout the whole professional career of employees, which enable employees to renew continuously knowledge structure, study the most advanced knowledge and technique and advance together with the enterprise so as to become the most stable and reliable talent resource.

3) As for the achievement management, build diacritical and human-orientated achievement mechanism, and carry out the innovative management mode. When establishing achievement management mechanism, the enterprise shall make it different from the system design for general employees, and keep the human-orientated as possible as it can. Because the work characteristics of knowledge-enabled employees differ from that of general employees, and traditional supervision and achievement check mode are hard to conduct efficient control on the work course. For example, the labor achievements of knowledge-enabled employees are hard to quantify, besides, which sometimes cannot be transformed into productivity quickly, meanwhile, considering that what the knowledge-enabled employees do during the labor course are creative activities and what they use are thought, so it is difficult to monitor the labor course. Meanwhile, the knowledge-enabled human resource endures higher work pressure and the creative work needs higher requirements, therefore, when designing the achievement management system, more attentions shall be paid to the key points to stir the internal drive. Sometimes, the loose and harmonious work environment, simple and equal public relations may help them invest more energy to the work and create more valuable work achievements. Set up flexible achievement management mechanism and carry out flexible management modes. On the one hand, via creating the work environment of trust, mutual respect and cooperation and favorable communication environment, the enterprise can provide employees with a stage to fully exert and show the energy; On the other hand, the enterprise shall introduce competition mechanism and create fair and rational 
competition environment for knowledge-enabled employees, which will bring internal drive and restriction for their behaviors. Take multiple measures for award or punishment to knowledge-enabled employees, create opportunities for the development of diligent knowledge-enabled employees, place pressure to the employees who are slack in the work and promoted for changing the work attitude.

4) Consider characteristics of career of knowledgeenabled human and establish rational salary structure and level. In the opinion of Frederick Herzberg, the opposite of satisfaction is dissatisfaction and the opposite of dissatisfaction is no dissatisfaction. So the high salary for high knowledge-enabled employees just makes knowledgeenabled employees have little dissatisfaction but no satisfaction.

For the knowledge-enabled employees, they own certain knowledge and skills, which are rare in markets, and the high salary is a general phenomenon, all of these just make they have no dissatisfaction but no satisfaction. The single high salary is just an affirmation to improving their material life; but sometimes far to attract and keep the talents. The enterprise shall fully know the demand and vocational development will of employees, provide them with feasible salary structure and level, and provide sometimes development space for individual development as well as more rights and responsibilities, the favorable public communication and atmosphere, spirit and emotion and other non-material reward may produce large influence. Accordingly, based on the post resources and staged characteristics of knowledge-enabled human resource held, the enterprise shall establish corresponding salary level and structure, and regard the proportion of non-financial reward in the salary structure if necessary.

5) Unique enterprise is an invisible asset to retain talents. In our opinion, the enterprise shall master the advantageous resource of its own and create unique enterprise culture of its own especially for the enterprises that owns a great number of knowledge-enabled human resources. Based on team, forgiveness and harmonization the enterprise culture of "study, cooperation, innovation and share" will provide the growth and development of knowledge-enabled employees with a nice work atmosphere, and the favorable enterprise culture will have positive pole to the knowledge-enabled employees, and a privity is formed between the enterprise and employees, to build a mutually believable relationship network may change the low level restriction and control to the self-conscious consciousness of knowledge-enabled employees. To raise the senses of responsibility, adscription and self-identity of knowledge-enabled employees to the enterprise will help stir their work enthusiasm and creativity.

\section{REFERENCES}

[1] Firmly March on the Path of Socialism with Chinese Characteristics and Strive to Complete the Building of a Moderately Prosperous Society in All Respects, Nov 2012

[2] Path Selection for the Innovation-Driven Development Strategy, Chen Xi, [J] Economic Issues, Mar 2013
[3] Caring and Building Talent Fostering Highland to Provide Intellectual Support for Building the Central Plains Economic Region [J] Henan Education (M), 2011 (01)

[4] Study on Solid Evidences of Excitation Factors for Knowledgeenabled Employees, Chen Jing'an, Scientific Technical Management 2005

[5] Fostering Excellent Talents to full Serve the Central Plains Economic Region Building [J] Wu Tingwei, Henan Education (M) 2011(01)

[6] Enterprise Culture Knowledge-enabled Human Resource Management [J], Zhang Meili, Operation and Management Jan, 2013

[7] Overall Study on the Excitation upon Knowledge-enabled Employees, Ju Qiong, Technical Market Economy Mar 2013.

[8] Discussion on Cultural Drive to Technical Innovation, Yi Xianfei, Li Zhaoyou, Zhang Yang [J] Scientific and Technical Management Research 2009(07)

[9] Thought of System Design for Implementing Innovation-driven Development Strategy, Huang Ningyan, [J] China Soft Science, April 2013 